\title{
Os historiadores e o tempo: a contribuição dos Annales
}

Historians and time: the contribution of the Annales

\author{
José Costa D’Assunção Barros*
}

\section{Resumo}

Este artigo tem por objetivo examinar a relação entre Tempo e História, de acordo com algumas das concepções desenvolvidas pelos historiadores pertencentes ao movimento dos Annales. Uma atenção em especial é dedicada à discussão sobre o conceito de "longa duração" em autores como Marc Bloch, Fernando Braudel e Michel Vovelle. Entre outros itens, discutem-se as relações entre evento e estrutura, bem como os diferentes esquemas para concepção da "longa duração", a dialética entre as distintas durações, e a interação entre Presente, Passado e Futuro na operação historiográfica.

Palavras-chave: Tempo; Duração; Annales; Historiadores.

\begin{abstract}
This article aims to examine the relation between Time and History according to some of the conceptions developed by the historians belonged to the Annales movement. A particular attemption is given to the discussion about the concept of "long duration" in authors such as Marc Bloch, Fernand Braudel e Michel Vovelle. Among others items, we discuss the relations between event and structure, the different schemes to conceive the "long duration", the dialectic between these different durations and the interaction between Present, Past and Future in the historiographic operation.
\end{abstract}

Keywords: Time; Duration; Annales, Historians.

\section{Os historiadores e novos modos de tratar o Tempo}

Um dos grandes movimentos historiográficos do século $\mathrm{XX}$, como se sabe, foi constituído pela chamada Escola dos Annales, cuja repercussão foi grande no Brasil, ao deixar um legado que, até os dias de hoje, influencia os nossos historiadores. As contribuições dos Annales foram muitas - desde o combate a favor da história-problema contra a história factual até uma especial atenção às interdisciplinaridades. Neste artigo, desenvolveremos um conjunto de considerações sobre uma das contribuições que mais chamam atenção em historiadores dos Annales, tais como Marc Bloch, Lucien Febvre, Fernand Braudel, entre outros: as novas formas de se relacionar com o tempo.

\footnotetext{
* Doutor em História pela Universidade Federal Fluminense (UFF). Professor da Universidade Federal Rural do Rio de Janeiro (UFRRJ).
} 
Quando falamos em novas possibilidades de relações entre os historiadores e o tempo, temos em vista os aspectos que vão da percepção do tempo histórico às possibilidades de representá-lo, de utilizá-lo como aliado para produzir inovadoras leituras da história, isto é, pensar inusitados objetos e mobilizar novos tipos de fontes históricas. Não obstante, o trabalho mais sofisticado sobre o tempo histórico tornou-se um item central no programa dos Annales. Essas novas possibilidades, evidentemente, não foram exclusivas dos historiadores dessa escola, constituindo desdobramentos para os estudos de historiadores diversos no decorrer do século $\mathrm{XX}^{1}$.

Particularmente, com Braudel e os annalistas que o seguiram em sua própria geração e na seguinte, encontramos um novo modo de conceber e representar o tempo a partir da articulação entre dois conceitos importantes: o de "longa duração" e o da "multiplicidade de tempos históricos"2. Ao assimilar uma noção de "estrutura" que já se desenvolvia na Linguística e na Antropologia da primeira metade do século XX, os annalistas inovam, concebendo-a como movimento. De igual maneira, conceitos apenas aparentemente antagônicos, como evento e estrutura, encontram uma nova forma de articulação com a perspectiva da "longa duração"3.

O olhar longo proporcionado pela "longa duração" é ainda revelador de aspectos que "só podem ser percebid[o]s quando o recorte é bastante amplo, isto é, talhado ao fio dos séculos" (VOVELLE, 2011, p. 376). De maneira semelhante, pensar a "longa duração" implica, como possibilidade, uma nova postura do historiador frente às fontes históricas (FOUCAULT, 1995, p. 3-20)4. "Longa duração" e "série documental", embora não constituam instâncias necessariamente interdependentes, apresentam-se

\footnotetext{
1 Para um exame das diversas formas de trabalhar as temporalidades, ver o texto de Immanuel Wallerstein: "The invention of time-space realities: Towards an understanding of our Historical Systems" (1991).

2 No verbete "Escola dos Annales", do Dicionário de Ciências Históricas (1986), André Burguière considera a Longa Duração como “o arco da aliança da Escola dos Annales” (1993, p. 52).

${ }^{3}$ No artigo sobre "A Longa Duração" (1958), em que voltaremos algumas vezes neste artigo - Fernando Braudel lembra que "evento" e "estrutura" não precisam estar, necessariamente, em campos opostos: "Um acontecimento, a rigor, pode vir carregado de uma série de significações e elos. Às vezes, ele é testemunha de movimentos muito profundos e, pelo jogo factício ou não das 'causas' e dos 'efeitos' tão caros aos historiadores do passado, anexa-se a ele um tempo muito superior à sua própria duração. Extensível ao infinito, ele se liga, livremente ou não, a toda uma cadeia de acontecimentos, de realidades subjacentes e, ao que parece, impossíveis de se destacarem, desde então, umas das outras" (BRAUDEL, 2011, p. 90).

${ }^{4}$ Michel Vovelle, por sinal, inverte o problema, para perguntar em seu artigo intitulado História e Longa Duração (1978): "Essa modificação do tempo, ou dos tempos da história, não seria, no fundo, apenas o produto de uma mudança na própria noção de fonte histórica?” (VOVELLE, 2011, p. 386).
} 
como proposições complementares em muitos dos trabalhos dos novos historiadores que abraçaram a perspectiva da História Serial.

No entender de Michel Foucault em Arqueologia do Saber, a possibilidade de se estabelecer séries massivas de documentos, nas quais cada fonte deixa de ser isolada para passar a ser percebida em um conjunto mais amplo que se estende cronologicamente, foi mesmo o que habilitou o historiador a atuar em um registro mais extenso, ao atentar-se para as permanências e as variações graduais. A "longa duração" deriva da "série", diz-nos o filósofo francês. Nada impede, em contrapartida, que a "série" seja também empregada no estudo de processos de ritmo mais acelerado.

\section{O conceito de "longa duração"}

O grande desafio a ser enfrentado pelos historiadores dos Annales a partir de Fernand Braudel estava na necessidade em superar o paradoxo de conciliar o tempo da história - sem o qual esta não pode ser pensada como campo de saber - com a "estrutura" atemporal que vinha sendo proposta por setores específicos da Antropologia, da Linguística e de outras ciências humanas. Em uma palavra, tratava-se de enquadrar a mudança histórica na estrutura da "longa duração". Uma possibilidade de abordar a questão é a de considerar que, se no âmbito mais amplo da "longa duração", o tempo se apresenta estrutural, em seu interior podem ocorrer mudanças a serem compreendidas pelo historiador. Fernando Braudel, em seu célebre artigo A Longa Duração (1958), evoca o exemplo da Economia:

\footnotetext{
A dificuldade, por um paradoxo apenas aparente, é vislumbrar a longa duração no campo em que a pesquisa histórica acaba de obter inegáveis sucessos: o campo econômico. Ciclos, interciclos, crises estruturais ocultam aqui as regularidades, as permanências de sistemas, ou de civilizações, como disseram alguns - isto é, velhos hábitos no que diz respeito ao modo de pensar e agir, condicionamentos resistentes, duros de mover, às vezes até mesmo contra toda alógica (BRAUDEL, 2011, p. 96-97).
}

Conforme se vê, a perspectiva da "longa duração" deve vir acompanhada da percepção de que os ritmos dos diversos processos históricos não precisam necessariamente coincidir-se. O mundo agitado da política do dia a dia - ou, para dar um exemplo mais recente que Braudel não poderia ainda evocar em sua época, das inovações tecnológicas que se assomam desde as últimas décadas do século $\mathrm{XX}$ - pode contrastar com o ritmo lento das mentalidades, das relações mais amplas dos homens 
com o espaço geográfico e das mudanças estruturais na língua por meio das quais os indivíduos se comunicam.

Para as mudanças políticas, tornou-se célebre a metáfora braudeliana das "espumas" formadas nas cristas das grandes ondas históricas. A esta convivência entre distintos ritmos do tempo histórico - ou mais especificamente das diferentes durações Fernando Braudel se referiu nos termos de uma "dialética das durações" (BRAUDEL, 2011, p. 89). Um esquema visual pode nos facilitar a compreender a dialética das durações como uma espécie de arquitetura, na qual a estrutura de ritmo mais longo (a "longa duração") enquadra os ritmos de duração mais rápida.

Figura 1: uma arquitetura de durações.

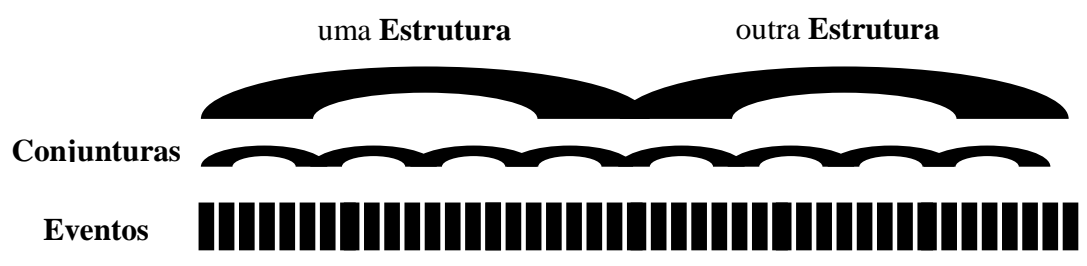

Pensar a dialética das durações como arquitetura é apenas uma possibilidade. Obviamente que os diversos processos históricos não se ajustam uns aos outros como se fossem peças bem encaixadas em um esquema arquitetônico. De todo modo, a metáfora da arquitetura permite entender, ainda que de maneira simplória, a possibilidade de convivência e a articulação dos diferentes ritmos históricos. Ao se mostrarem regidas por um tempo lento que determina seu alargado arco externo de permanências - e ao admitir dentro de si mesmas o contraponto de ritmos mais entrecortados -, as estruturas reafirmam, aqui, a sua própria instância histórica, abaixo e acima de si, notando-se que uma estrutura poderia ser contraposta a outra em termos de alteridade (e não de continuidade).

No interior de uma estrutura de "longa duração", representada visualmente na parte superior do esquema, poderiam ser abordadas pelo historiador as média e curta duração (ou os tempos das conjunturas e dos eventos), de modo que o projeto braudeliano de durações enquadradas conseguiria estabelecer uma conciliação entre o tempo agitado da história política tradicional e o tempo imóvel das ciências sociais emergentes. A metáfora da arquitetura de durações é autorizada pelo próprio Fernand 
Braudel, ao buscar uma delimitação e elucidação do conceito de "estrutura", tal como este poderia ser utilizado pelos historiadores:

\begin{abstract}
Para nós, historiadores, uma estrutura é sem dúvida um agregado, uma arquitetura; porém, mais ainda, uma realidade que o tempo pouco deteriora e que veicula por um longo período. Certas estruturas, por perdurarem durante muito tempo, tornam-se elementos estáveis de uma infinidade de gerações: elas obstruem a história e, pelo fato de a incomodarem, impõem seu desabamento. Outras são mais propícias a se desestruturar. Mas todas são, ao mesmo tempo, sustentáculos e obstáculos. Com obstáculos, elas ficam marcadas como limites (contornos, no sentido matemático) dos quais o homem e suas experiências praticamente não podem se libertar. Pensem na dificuldade de quebrar algumas limitações geográficas, algumas realidades biológicas, alguns limites da produtividade e mesmo certos condicionamentos espirituais: os arcabouços mentais também são prisões de longa duração [Fernando Braudel, A História e as Ciências Sociais: a Longa Duração, 1958] (BRAUDEL, 2011, p. 95).
\end{abstract}

Neste texto, Fernand Braudel menciona tanto a possibilidade de estruturas que apresentam fissuras entre si (as estruturas contra as quais "impõe-se o seu desabamento" para que outras possam surgir) quanto a ocorrência de estruturas que deslizam lentamente até desaparecerem, ou até se transformarem em novas estruturas, com características distintas e novos padrões de coerência. De acordo com as próprias palavras de Braudel, temos, aqui, as estruturas que "são mais propícias a se desestruturar". Em um caso, a passagem de uma estrutura a outra pode ser regida por mudanças ou declives abruptos e, certamente, aqui, podem ser incluídas as revoluções sociais, compreendidas como movimentos contra as estruturas que "obstruem a história".

Podemos agregar ainda o exemplo das revoluções tecnológicas que, em alguns casos, constituem poderosos eventos capazes de desestruturar, de assalto, uma antiga estrutura. Basta pensar nos eventos tecnológicos que, nas últimas décadas, mudaram a face do mundo da comunicação humana por meio de uma irreversível revolução digital. Acontecimentos políticos de grande porte - como a desestruturação do socialismo real na antiga União Soviética e o desabamento do muro de Berlim entre as duas Alemanhas - podem, também, ser evocados como exemplos de eventos que proporcionaram a passagem de uma estrutura para outra. Nesse caso, seria interessante discutir se acontecimentos como esses é que introduziram uma fissura na estrutura política anterior ou se, na verdade, foram resultados de longos e imperceptíveis processos sociais e políticos que já vinham acumulando tensões no interior da própria estrutura até que essas rupturas tornaram visíveis e irreparáveis devido a um acontecimento emblemático e impactante. 


\section{O Evento e a "longa duração"}

As relações entre evento e estrutura, no âmbito das propostas do movimento dos Annales para a discussão conceitual sobre a "longa duração", envolve questões complexas. Os eventos podem fundar estruturas? Em seu artigo intitulado, História e Longa Duração, Michel Vovelle (2011, p. 399) evoca, exemplificativamente, a tese de Paul Bois sobre Camponeses do Oeste da França (1960). Ao perceber no campesinato francês do século XIX uma profunda cisão entre monarquistas (no oeste) e republicanos (no leste), nitidamente separados por uma fronteira espacial, Paul Bois chegou àa conclusão a respeito do "ponto de fratura" na Revolução Francesa:

Paul Bois partiu de uma estrutura e encontrou um acontecimento; sem que haja contradição alguma nisso, outros partem de um acontecimento e redescobrem uma estrutura (VOVELLE, 2011, p. 400) ${ }^{5}$.

O evento pode assumir, em relação à estrutura, papéis diversos a serem decifrados pelos historiadores. Ao contrário da ruptura que separa as duas estruturas, o evento pode se apresentar, em uma análise historiográfica, como o elo que permite a passagem entre duas estruturas distintas. A Peste Negra, evocado por Le Roy Ladurie, proporciona possibilidades interpretativas distintas. Reinscrita em uma história global mais ampla no espaço-tempo, o evento em questão - fenômeno que o olhar curto e escatológico transforma em uma espécie de terrível raio que se abate sobre a demografia europeia - vê-se vertido em um episódio previsível no processo de "unificação microbiana do mundo":

Tomemos como exemplo a peste negra de 1348, que, no Ocidente, extermina um terço e, às vezes, até a metade das populações. Analisada com bastante distanciamento, e de um ponto de vista internacional ou intercontinental, essa epidemia perde o seu caráter teratológico. Ela passa a ser percebida apenas como um episódio previsível, no seio do processo de conjunto engajado do século XIV ao XVI, e que poderia ser chamado de unificação microbiana do mundo; sendo tal unificação em si mesma condicionada pelos fenômenos globais que ocorrem desde o século XI, tais como o crescimento demográfico de três grandes massas humanas (a chinesa, a européia, a ameríndia) e a conseqüente comunicação - inelutável - dessas massas umas com as outras, depois da abertura de rotas continentais e marítimas, militares e comerciais (LE ROY LADURIE, 2011, p. 249). ${ }^{\circ}$.

Como dizíamos, o evento também pode se oferecer, no seio de uma análise historiográfica, como um elo entre duas estruturas. Assim, se o acontecimento pode ter a

\footnotetext{
${ }^{5}$ Sobre as teses de Paul Bois, ver ainda LE ROY LADURIE, p. 248-267.

${ }^{6}$ Sobre a "unificação microbiana do mundo", ver o artigo de Le Roy Ladurie que leva este mesmo título (1973). Para mais considerações sobre a dialética entre o evento e a estrutura, ver LE ROY LADURIE, 1972 (2012, p. 248-267).
} 
sua importância redimensionada, engolida pela estrutura construída pelo historiador ou até mesmo ser "fagocitado" pela estrutura (LE ROY LADURIE, 2011, p. 250), há ainda aqueles eventos ou processos incontornáveis que, tal como sinaliza Pomian (1978), são verdadeiros mediadores que proporcionam ou regem a passagem de uma estrutura a outra. Para esses casos, surge um novo diálogo conceitual que coloca em interação a "estrutura" e a "revolução". De fato, diz-nos Krzystof Pomian [1978], que "toda revolução nada mais é que a subversão de uma estrutura e o advento de uma nova estrutura" (1990, p. 120). O acontecimento, nesse caso, pode ser redimensionado como "acontecimento-processo" (ou "processo-acontecimento").

De acordo com essa perspectiva, o conceito de "revolução" pode ser ampliado: “[a revolução] é, não raro, silenciosa e imperceptível para aqueles que a fazem: é o caso da revolução agrícola ou da revolução demográfica. Inclusive, nem sempre ela é rápida, ela pode se estender por vários séculos" (POMIAN, 1990, p. 120). Em certo sentido, essa perspectiva coloca em revisão o caráter espetacular da revolução:

Uma revolução não é mais pensada como uma sequência de acontecimentos únicos. Ela é uma onda de inovações, que se propaga a partir de um ponto inicial, através de inumeráveis repetições: é uma a uma que as pessoas aprendem a ler e a escrever [para o caso da secular revolução da alfabetização]; é burgo após burgo e aldeia após aldeia que se vê o número de relógios se multiplicar. E é justamente essa série de repetições que é interessante na perspectiva da história estrutural, não alguns fatos espetaculares, mas isolados, ainda que não únicos (POMIAN, 1990, p. 120).

\section{Modelos de "longa duração": da arquitetura às estruturas flexíveis}

A perspectiva de visualizar a "longa duração" como uma "arquitetura de durações", tal como proposta por Braudel em seu artigo, A Longa Duração (1958), pode ser exemplificada com sua obra $O$ Mediterrâneo (1949), no qual o historiador francês mostra como a moldura do meio físico traz limites consideráveis às vidas dos seres humanos pertencentes às várias populações que habitam nas regiões do mar mediterrâneo:

O exemplo mais acessível [de estrutura de longa duração] parece ser o do meio geográfico. O homem é prisioneiro durante séculos, de climas, vegetações, populações animais, culturas, de um equilíbrio lentamente construído, do qual não pode se desviar sem provocar o rompimento de tudo ao seu redor. Observem o papel ocupado pela transumância na vida das populações das montanhas, a permanência de alguns setores da vida marítima, enraizados em certos pontos privilegiados do litoral; vejam ainda a durável implantação das cidades, a persistência das rotas e vias de tráfego, a fixidez surpreendente do quadro geográfico das civilizações [BRAUDEL, História e as Ciências Sociais: a Longa Duração, 1958] (2011, p. 95). 
As mentalidades, conforme veremos mais adiante a partir das contribuições dos historiadores da terceira geração dos Annales e da Economia, podem oferecer exemplos adicionais de estruturas de "longa duração". Vamos considerar por ora o âmbito da Economia. É muito comum que os historiadores econômicos considerem as conjunturas marcadas pelo eterno retorno dos ciclos econômicos e das crises do capitalismo. Todavia, aqui estaremos ainda no âmbito dos ritmos de média duração, com ciclos que abarcam algumas dezenas de anos.

Para buscarmos, na história econômica, estruturas de "longa duração", precisamos alcançar, pelo menos, o nível secular. Consideremos um exemplo da obra de Braudel escolhida por José Carlos Reis - historiador brasileiro que examinou a contribuição dos Annales em seu livro Nouvelle Histoire e Tempo Histórico (1994, p. 87) - e construamos um esquema visual que ajudará a esclarecer como funciona o tempo braudeliano. O exemplo é extraído do já mencionado estudo de Braudel, cujo título pode ser simplificado, para facilitar, como o $O$ Mediterrâneo (1949). A certa altura de $O$ Mediterrâneo, Braudel discorre sobre a estrutura de longo crescimento econômico que teria caracterizado o século XVI, na Europa. Vejamos isto representado na figura proposta:

Figura 2: O Tempo dos Annales.

\begin{tabular}{|l|l|l|l|}
\hline $\begin{array}{l}\text { Uma } \\
\text { Longa } \\
\text { Duração } \\
\text { (período } \\
\text { anterior) }\end{array}$ & \begin{tabular}{c|c} 
Uma Longa Duração \\
(Estrutura de Crescimento Econômico)
\end{tabular} & $\begin{array}{l}\text { Outra } \\
\text { Longa } \\
\text { Duração } \\
\text { Fase 1: }\end{array}$ \\
$\begin{array}{c}\text { Crescimento } \\
\text { Acelerado }\end{array}$ & $\begin{array}{l}\text { Fase 2: } \\
\text { Crescimento } \\
\text { Declínio } \\
\text { Econômico }\end{array}$ \\
\hline
\end{tabular}

Fonte: BRAUDEL, 1984.

No exemplo acima, uma nova estrutura econômica começa em 1470, trazendo um crescimento econômico acelerado até o período que medeia os anos 1570 e 1600 . A partir daí, o crescimento desacelera um pouco, mas ainda é significativo. Somente em 1650, em decorrência da percepção de uma crise estrutural que pode ser identificada entre 1623 e 1650, é que Braudel identifica uma quebra da estrutura, iniciando-se, em 
seguida, uma bem distinta, agora de declínio econômico. No interior de uma estrutura, como já ressaltado, é perfeitamente possível desdobrar uma dinâmica envolvendo as demais durações - tal como fez Braudel, no plano mais geral, com a divisão tripartida da sua obra sobre $O$ Mediterrâneo (1949), na qual o volume inicial corresponde à "longa duração" ditada pelas relações dos seres humanos com o grande espaço geográfico em torno do mar Mediterrâneo, e os dois volumes seguintes já correspondem aos processos de média e curta duração inseridos nessa estrutura maior.

O exemplo acima proposto, em comparação com a longuíssima duração ditada pelas relações do homem mediterrânico com o espaço, mostra-nos um ritmo de duração um pouco mais acelerado, no qual configura-se uma estrutura demarcada por um recorte de tempo de 180 anos. No interior dessa estrutura quase bicentenária, Braudel percebeu duas fases distintas (crescimento acelerado e crescimento desacelerado). É possível também assinalar, no interior do processo, os recortes de crise, no qual a estrutura já deixa que sejam entrevistos os seus abalos. O período de 1623 a 1650 é discutido por Braudel como uma crise estrutural. Com o exemplo, pretendemos mostrar que, no interior de uma estrutura, novos recortes podem ser realizados pelo historiador e novos padrões de ritmo histórico podem ser identificados com relação a determinadas questões.

A dialética das durações também pode ser aplicada à relação entre os distintos âmbitos historiográficos que são frequentemente construídos pelos historiadores: o social, o econômico, o político, as mentalidades, e assim por diante. Se pensarmos, por exemplo, na articulação entre diversas instâncias ou dimensões do mundo históricosocial, tais como a espacialidade das sociedades humanas, a economia e a política, torna-se possível articular durações diversas em uma única arquitetura. Basta nos conscientizarmos de que certos tipos de processos ou acontecimentos costumam perdurar menos ou mais do que outros, oferecendo diferentes ritmos de transformação ou permanência.

É oportuno termos em vista ainda que, embora seja possível dizer, de modo geral, que o patamar político oferece ao historiador processos regidos por ritmos mais acelerados que a economia, e esta se mostre mais rápida que o plano das mentalidades, é perfeitamente possível pensar em processos políticos de média ou longa duração, uma vez que consideremos o patamar político como aquele no interior do qual se desdobram as relações de poder e os processos e eventos concernentes a elas. 
A dominação masculina, por exemplo, pode ser considerada uma estrutura de poder de longuíssima duração. A aliança entre Igreja e Estado no Ocidente, que pode ser igualmente vista como uma estrutura historicamente extensa e de "longa duração", tem abarcado séculos. Por outro lado, é inegável que em certos sistemas políticos os governos se sucedam rapidamente (o próprio modelo democrático de sucessão eleitoral, por exemplo, dita um ritmo específico). Os acontecimentos políticos de superfície, mais ainda, costumam mostrar um ritmo acelerado, e não é por acaso que Braudel se referiu a eles por meio da metáfora da "espuma dos acontecimentos".

A articulação possível entre as durações - sempre uma construção do historiador, e nunca um dado da própria realidade - permite ainda questionar sobre qual seria o melhor modelo para o trabalho historiográfico. Seria a perspectiva ideal a da "arquitetura de durações", esta imagem que parece ter originado o modelo formal mais utilizado por Fernando Braudel, mas que, na verdade, se desenvolve ao lado da plena consciência desse historiador de que o tempo histórico, em sua complexidade, também pode ser pensado nos termos de uma "multiplicidade de descidas pelos diversos e incontáveis rios do tempo"? (BRAUDEL, 2011, p. 104). No modelo da "arquitetura das durações", as diferentes durações se encaixam umas nas outras em um enquadramento múltiplo. Trata-se, de fato, de um modelo funcional, prático, provedor de uma boa organização para a representação historiográfica.

\section{Figura 3: enquadramento de durações}

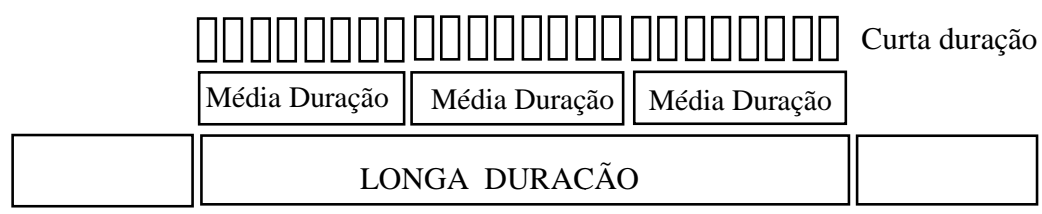

De nossa parte, nos perguntamos se não seria mais apropriado pensar na imagem da "polifonia de durações". Nessa segunda proposta, inspirada no modelo da música, as diferentes durações que envolvem os diversos processos históricos podem se apresentar em defasagem, à maneira das melodias diversas - cada qual portadora de seu próprio ritmo e se desenvolvendo em distintos caminhos - o que não impede, em contrapartida, que essas diferentes melodias ou "rios de tempo" desenvolvam-se conjuntamente no interior de uma mesma música. 
Figura 4: imaginação sobre uma "polifonia de durações"

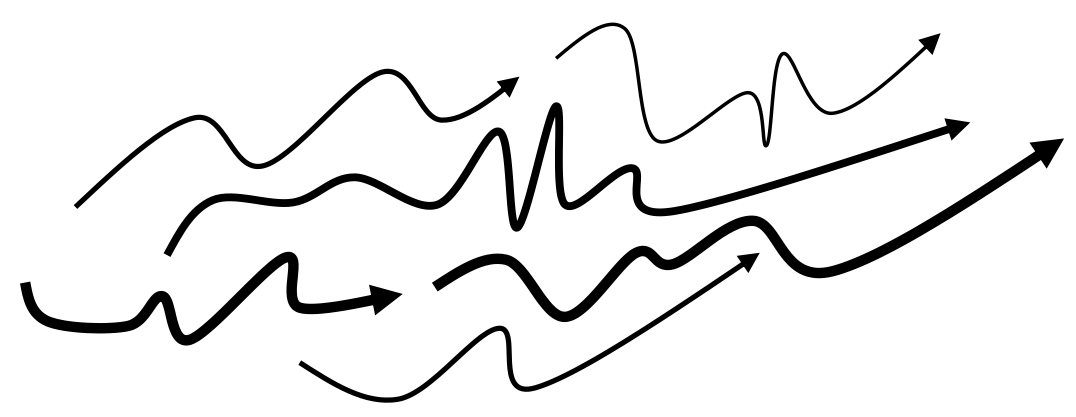

Consciente do problema da representação historiográfica da dialética de durações, em seu artigo, A Longa Duração (1958), Braudel nos oferece uma de suas imagens mais belas, por meio da qual desenha em palavras um pouco da extrema complexidade do devir histórico:

De fato, na linguagem da história (tal como a imagino), não há como existir sincronia perfeita: uma parada instantânea, suspendendo todas as durações, é em si quase absurda, ou, o que dá no mesmo, muito fictícia; do mesmo modo, uma descida pela encosta do tempo só é concebível sob a forma de uma multiplicidade de descidas pelos diversos e incontáveis rios do tempo [Fernando Braudel, História e Ciências Sociais: a Longa Duração, 1958] (2011, p. 104).

É também uma leitura mais flexível da dialética das durações aquela que o historiador Michel Vovelle (1933), relacionável à chamada terceira geração dos Annales, oferece-nos em algumas de suas obras, tal como aquela no qual expõe os resultados de sua pesquisa em As Metamorfoses da Festa na Provença entre 1750 e 1820 (1976). Em seu artigo teórico sobre A Longa Duração (1958), aliás, Michel Vovelle chega a utilizar, ainda que de passagem e mais discretamente, a própria metáfora da música:

Decorrência direta destas leituras, perfila-se a ideia de uma independência dos tempos da história sinfônica, em que os diferentes ritmos enfim decifrados se entrelaçariam num todo coerente ou, ao contrário, entrariam em colisão em duas divergências [Michel Vovelle, História e Longa Duração, 1958] (2011, p. 392).

Existem algumas vantagens a destacar nas concepções mais flexíveis sobre o conceito de estrutura. Em sua conexão com a vida, a dialética das durações, que pode ser apreendida por meio de uma imaginação mais musical do que arquitetônica, ou mais 
de acordo com a metáfora líquida dos rios do que com a metáfora arquitetônica dos edifícios. A principal vantagem é que a concepção flexível das estruturas - além de admitir como uma de suas variantes a própria concepção braudeliana das estruturas que se sucedem umas às outras - permite também pensar em estruturas que se entrelaçam, que se "encavalgam", ou seguem caminhos divergentes, sem cancelarem umas às outras.

Suponhamos um problema histórico específico como a questão das "atitudes do homem diante da morte" - tema da história das mentalidades que foi examinado tanto por Michel Vovelle quanto por Philippe Ariès (1914-1984). Admitindo que as formas de sensibilidade do homem diante da morte tenham se modificado ao longo do tempo, o que parece francamente evidente para os historiadores, podemos pensar nos grandes padrões que se sucederam ou que se afirmaram historicamente, cada qual perdurando durante muito tempo.

Vivemos em uma época, cuja morte é envolvida por um grande tabu. O homem ocidental - se pudermos fazer um recorte espacial abrangendo a Europa e as Américas para facilitar - procura afastar, sistematicamente, de si a visão da morte, isolando-a sempre que pode em uma espacialidade definida que é a dos cemitérios e em uma temporalidade específica que é a dos rituais privados. Com muita dificuldade esse homem ocidental dos últimos séculos tem contemplado a possibilidade de sua própria morte ou daqueles que lhes são próximos, senão a partir de subterfúgios ou para atender a demanda de questões práticas (o testamento que precisa ser feito, ou o seguro de vida). Jamais um ser humano ocidental daria ao seu pai ou à mãe, de presente de aniversário, um caixão - como fazem os camponeses, ainda hoje, em certas regiões da China quando querem honrar e expressar uma grande gratidão a seus pais.

Entre a nossa atual civilização ocidental e as outras culturas, podemos vislumbrar diferentes estruturas mentais concernentes à sensibilidade diante da morte. Contudo, de acordo com diversos historiadores das mentalidades, a nossa atual atitude frente à morte - ou a atual estrutura mental que impõe aos homens ocidentais certos limites ao seu complexo de atitudes - é bem distinta da relação com a morte que os homens desse mesmo circuito civilizacional tinham em outras épocas.

A morte, outrora, pode ter sido uma festa, pública, e não familiar ou individual, vislumbrada de frente com muito mais tranqüilidade. Sem espaço, neste artigo, para esmiuçar com maiores detalhes esse problema, admitiremos a ideia de que, no decurso de sua história, distintas mentalidades relacionadas à morte já estruturaram a vida dos 
homens europeus e das sociedades americanas que herdaram parte de sua cultura (abstraremos, nesse momento, para não complicar muito, o fato de que as culturas americanas são híbridas e que, no caso do Brasil, possuem uma igual herança advinda das sociedades africanas e indígenas).

Se existiram diferentes estruturas mentais relacionadas à morte, como propõem os historiadores das mentalidades, como se expressaram essas estruturas ao longo de nossa história? Umas foram se sucedendo às outras em grandes blocos que só podiam existir um de cada vez? Ou elas foram emergindo, historicamente, sem cancelar, de imediato, as estruturas em declínio, produzindo aquilo que Michel Vovelle vislumbrou por meio de um modelo no qual as estruturas se "encavalgam" umas às outras, de modo a produzir "um entrelaçamento e um encaixamento, como as telhas de um telhado"?? Para esse caso, se preferirmos, também podemos utilizar a imagem musical das diferentes melodias que coexistem em forma de cânon, cada qual surgindo sem que a outra tenha ainda terminado:

Figura 5: estruturas em canon

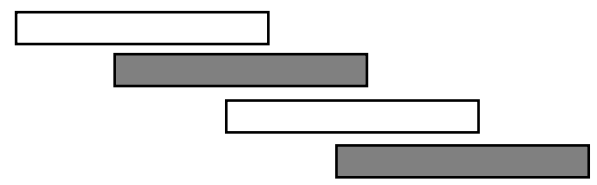

Evocar a metáfora musical também nos permite perguntar: essas estruturas (ou melodias de "longa duração") podem se entrelaçar, contaminando umas às outras?

\footnotetext{
${ }^{7}$ Para o caso do estudo das atitudes do "Homem diante da Morte", Vovelle cita o exemplo das próprias análises de Philippe Ariès, outro dos historiadores da terceira geração dos Annales: "Philippe Ariès, um dos descobridores dessa história, tanto no que diz respeito à criança como à família e à morte, afirma isso energicamente pelo exame dessas evoluções secretas no decorrer da longuíssima duração. Evoluções inconscientes também, pois passam despercebidas dos homens que as vivem. A imagem que ele nos dá delas, em especial em sua recente história da morte, não é a de uma história 'imóvel' [...]. mas, sim, a de amplos painéis da história, sucessão de estruturas ou de modelos de comportamentos que, mais do que em sucessão, têm existência em um entrelaçamento e em um encaixamento, como as telhas de um telhado: da morte 'domada', acrônica, que é aquela de Ivan Illitch tanto quanto do bravo Roland, a uma primeira conscientização do 'escândalo' da morte individual, da Idade Média à era [neo]clássica, e, depois, até a sua transferência para a morte do outro - o objeto amado - na idade romântica, antes de se chegar ao tabu que envolve a morte na época contemporânea" (VOVELLE, 2011, p. 385).

${ }^{8}$ Exemplo clássico de análise de estruturas que seguem se imbricando e interferindo umas na outras é o de autores que examinaram "o tempo duplicado das culturas populares - domínio da inércia das tradições - e o das culturas de 'elite', como se diz, sede da inovação e das provocações ... Cultura popular e cultura de elite: outra dialética maior, tema para interrogações atuais" (VOVELLE, 2011, p. 383). Clássico dessa análise, no âmbito da Escola dos Annales, é a obra de Robert Mandou intitulada A Cultura Popular nos séculos XVII e XVIII (1975). Em outras correntes, teremos os trabalhos derivados da vertente de Mikhail Bakhtin, que em Cultura Popular na Idade Média e no Renascimento (1965), expõe o problema da circularidade cultural, o que inspira, depois, uma análise similar elaborada pelo micro-historiador italiano Carlo Ginzburg em O Queijo e os Vermes (1976).
} 
Figura 6: melodias entrelaçadas

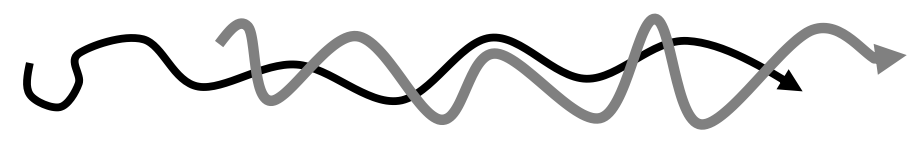

Ou distintas estruturas de "longa duração" podem conviver no tempo e seguir caminhos divergentes, como duas melodias que não se tocam e se situam em espaços "sonoros" bem separados?

Figura 7: estruturas coexistentes, mas divergentes

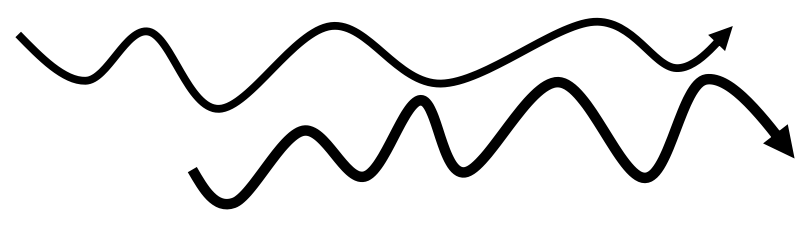

Quando pensamos em estruturas mentais, surge ainda outra questão, a qual se encontra em aberto. Podemos nos perguntar se uma estrutura mental relativa a um aspecto específico - retomemos, por exemplo, o problema histórico da atitude do homem diante da morte - estabelece, necessariamente, uma relação direta com outras esferas, como a da economia e da demografia, ou mesmo em relação a outros problemas na própria esfera das mentalidades (as atitudes frente à morte interagem com os modos de comportamento em relação às festas ou com os modos de perceber a infância nas várias épocas?). Ou existe certa autonomia de uma sucessão ou de um conjunto problemático de estruturas mentais? Ainda sobre o trabalho de Philippe Ariès, diz-nos Michel Vovelle, que o sucedeu (ou competiu com ele) no mesmo campo de investigações históricas:

Para ele [Ariès], uma história de longa duração, tão essencial quanto a das atitudes coletivas diante da morte, move-se com uma autonomia real em relação às pressões da demografia, das estruturas como representações sociais, e até mesmo, mais curiosamente, em relação às formalizações ideológicas, quer sejam elas religiosas ou filosóficas. É na autonomia de um 'inconsciente coletivo' movido por sua própria dialética interna, que Ariès segue os deslizes de longa duração, que dão ao fenômeno sua respiração própria [VOVELLE, História e Longa Duração, 1958] (2011, p. 393). 


\section{A aplicação do modelo estrutural aos diversos campos históricos}

À parte aos diferentes modelos visuais que podem ser pensados para entender a história estrutural, voltemos ao modelo mais funcional da "arquitetura de durações", o que deve vir sempre acompanhado do alerta de que, nesse caso, o historiador estará apenas lidando com uma representação, com um modo organizado de produzir sua reflexão historiográfica e de exibir os resultados de sua pesquisa. Modelos como o da "arquitetura de durações", atrás evocado, inclusive, considerando a possibilidade de envolver períodos ainda maiores, poderiam ser pensados também para outros campos históricos que não apenas a História Econômica, que foi a primeira modalidade historiográfica que acolheu o novo projeto de encaminhar uma dialética de durações ${ }^{9}$.

O modelo da história estrutural pode ser, de fato, aplicado a problemas históricos diversos, tais como a permanência e a mudança de padrões de mentalidade, os modos de relação do homem com determinado espaço, as persistências e mudanças no perfil demográfico de certa população ou o demorado perdurar de certo padrão cultural ${ }^{10}$. Pode-se mesmo pensar em longuíssimas durações também para esses diversos âmbitos. Assim, por exemplo, o já mencionado modelo de "dominação masculina”, com o qual estamos tão acostumados em uma civilização como a nossa, pode ser entendido como uma estrutura de longuíssima duração. No seu interior, com oscilações várias, podemos ter passado do predomínio da misoginia medieval para o padrão do machismo moderno em seus diversos níveis, incorporando, progressivamente, direitos políticos para a mulher e outras instâncias que começaram a atenuar, gradualmente, as desigualdades sociais geradas pelas diferenças de sexo; mas é difícil deixar de encarar o problema

\footnotetext{
${ }^{9}$ A História Econômica foi, certamente, o primeiro campo histórico no qual se elaborou uma dialética das durações: "A escola francesa, de Françoise Simiand e Ernest Labrousse, fez com que se admitisse a verdade, agora banalizada, da imbricação dos três tempos do economista: o tempo curto do ciclo decenal, com seu paroxismo convulsivo da crise - com sua duração de um ano ou mesmo de apenas uma estação do ano; o tempo médio do interciclo; o tempo longo, ainda que progressivamente diminuído da Idade Média para cá, do movimento de longa duração secular - as tradicionais fases A e B de Simiand. Essa dialética dos tempos da história econômica encontrou a perfeição e o acabamento máximos com a história dos preços, tal como esta se constituiu a partir das grandes séries exploradas, as mercuriales de preços dos grãos ou dos produtos fabricados - primeiros grandes triunfos de uma história quantitativa que ainda não se distinguia da história serial" (VOVELLE, 2011, p. 376).

${ }^{10}$ Braudel, em A Longa Duração, evoca - como exemplo de um estudo sobre uma estrutura relacionada à esfera da cultura - a obra Pintura e Sociedade, de Pierre Francastel (1951). Este assinala, para um período que vai desde os primórdios do Renascimento e até início do século XX, a permanência de um padrão pictórico figurativo que, por quatro séculos, se apoiou em um espaço geométrico e perspectivado, até que é finalmente interrompido pela revolução do Cubismo e de correntes diversas da "pintura intelectual" da Arte Moderna (BRAUDEL, 2011, p. 86). Poderia ser evocado outro exemplo, ainda mais representativo, agora de uma longuíssima duração na história da pintura: o da milenar pintura do Antigo Egito - esta que chega a atravessar milênios com os esquemas bidimensionais ancorados na "lei da frontalidade".
} 
histórico da dominação masculina como uma longuíssima duração que perdura e que somente se modifica muito lentamente. A história, em relação a um aspecto qualquer, nunca é imóvel, contudo, pode se mover menos ou mais lentamente, desenvolver-se ritmicamente como um adágio molto que lhe dará uma aparência externa de quase imobilidade, de algo que se transforma de maneira quase imperceptível em relação ao ritmo menos lento de outros aspectos.

O problema do deslizamento entre estruturas também deve ser considerado quando abordamos a dialética das durações. Foi o deslizamento de uma estrutura mental a outra que se tornou o principal objeto de estudo para Robert Mandrou, um historiador das mentalidades ligado à terceira geração dos Annales. Em Magistrados e Feiticeiros na França do século XVII (1968), esse historiador francês analisa uma mentalidade coletiva que perdurava já fazia alguns séculos e que havia sido o sustentáculo da perseguição a todas as práticas religiosas, místicas e culturais que não se adaptavam à versão oficial do cristianismo.

O século XVII, com o advento da modernidade, teria sido o patamar de deslizamento dessa estrutura mental para uma outra, radicalmente distinta. Como explicar esse problema histórico? O que teria ocorrido para que certas práticas de relacionamento do homem com a natureza, com a vida cotidiana, com os usos linguísticos e com seus credos pessoais - que antes eram consideradas como territórios do mal diretamente regidas pela atividade de Satã - subitamente passassem a ser vistas como doenças, vigarices, maneirismos, superstições, práticas culturais exóticas ou, pelo menos, assuntos que não deviam mais conduzir os seus praticantes à fogueira? ${ }^{11}$ Que elementos teriam presidido essa mudança de mentalidades? O que nos revelam essas transformações estruturais sobre o próprio advento da modernidade? O problema merece ser lembrado, não pela resposta de Mandrou no decurso de uma minuciosa pesquisa de fontes jurídicas e teológicas, mas antes pelas próprias indagações que ele levantou:

\footnotetext{
${ }^{11} \mathrm{Um}$ dos inúmeros exemplos trazidos por Mandrou nessa obra é o dos usos, na linguagem cotidiana, de expressões com menções ao diabo - antes consideradas como provas de comunicação com Satã, a serem punidas severamente, e agora relegadas ao âmbito dos meros maneirismos linguísticos. Os crimes de envenenamento, antes considerados como provas de ligação com forças malignas, eram agora punidos como assassinatos comuns, e não como signos da prática de feitiçaria. Cada um desses deslocamentos, e muitos outros, seriam, para Mandrou, elementos de um quadro maior de mudança de mentalidades.
} 
No início do século XVII, as perseguições de bruxaria ainda vão de vento em popa no seio do aparelho judiciário laico: essa enorme instituição repleta de pessoas instruídas tanto quanto isto é possível (mas não ainda 'esclarecidas') persegue implacavelmente e sem hesitações (salvo algumas exceções), os discípulos de Satã, os cúmplices de uma perversão horrenda que colocam em perigo a salvação dos homens. No final do mesmo século, todos os Parlamentos tinham renunciado a esse gênero de acusação e passam a lidar, então, apenas com os pastores envenenadores, os trapaceiros que abusam da credulidade pública e as falsas devotas. Como é possível que uma jurisprudência solidamente estabelecida por séculos de prática contínua possa ser questionada, discutida, e finalmente abandonada em apenas algumas décadas? [...] Por meio disto, é toda a concepção dos poderes que o homem exerce sobre a natureza e sobre os outros homens, sobre Deus e Satã, que se vê finalmente questionada. [...] Em uma palavra: o abandono das perseguições por crimes de bruxaria representa o deslocamento de uma estrutura mental que foi parte integrante desta divisão do mundo durante séculos (MANDROU, 1968, p. 23).

Em um importante artigo sobre a História das Mentalidades (1978), Philippe Ariès, um dos mais notórios historiadores das mentalidades, traz a tese de Mandrou sobre a "perseguição à bruxaria" como um dos quatro exemplos sobre deslocamentos de estruturas de longa duração relativas às mentalidades. Os outros três exemplos são (1) as mudanças de atitudes mentais relativas à conservação da riqueza e ao pagamento de impostos, (2) as mudanças de expectativas em relação ao tempo cotidiano a partir do século XIII, e (3) as mudanças nos seculares hábitos de contracepção na França de fins do século XVIII. Cada um desses problemas históricos evidencia estruturas de longa duração relacionadas às mentalidades que, por motivos diversos que são precisamente os objetos de pesquisa, terminam por declinar ou se transfigurar em novas estruturas mentais $^{12}$.

Ao mesmo tempo em que a História nos oferece estruturas de solidez impressionante como as que regem relações de algumas sociedades com seus meios naturais, ou como as de mentalidade - estruturas que parecem resistir ao assédio de eventos externos e à eclosão dos eventos internos ou que, depois de os produzirem, reassimilam-os, sem modificações visíveis, em seus elementos fundamentais - também podem ser percebidas, pelas construções historiográficas, as estruturas mais flexíveis e as que se transformam mais radicalmente diante das reviravoltas, mesmo que perdurando em suas bases essenciais. O contraste entre a história das mentalidades e a história das idéias nos oferece exemplos relevantes. Distintos da solidez das estruturas mentais como a da "dominação masculina", os historiadores podem estudar a

\footnotetext{
${ }^{12}$ O artigo de Ariès foi publicado na coletânea A Nova História (1978), coordenada por Jacques Le Goff (ARIÈS, 1990, p. 154-176).
} 
persistência mais entrecortada de certos sistemas de pensamento ou da assimilação de determinados núcleos de ideias. Braudel dá-nos o exemplo da assimilação das propostas de Maquiavel no moderno pensamento político, em contraposição à inabalável persistência dos mitos nas sociedades naturais:

\begin{abstract}
Os mitos, lentos em seu desenvolvimento, correspondem eles também a estruturas de extrema longevidade. É possível, sem se preocupar em escolher a mais antiga, colecionar versões do mito de Édipo, em que o problema consiste em arranjar as diversas variações e esclarecer, subjacente a elas, uma articulação profunda que as comanda. Mas suponhamos que nosso colega [historiador] se interesse não por um mito, e sim por imagens, por interpretações sucessivas do 'maquiavelismo', que ele busque elementos de base de uma doutrina bastante simples e muito difundida, a partir de seu lançamento real no século XVI. A cada instante, aqui, quantas rupturas, quantas reviravoltas, até na própria estrutura do maquiavelismo, pois esse sistema não tem a solidez teatral, quase eterna, do mito; ele é sensível aos incidentes e saltos, às intempéries múltiplas da história. Em uma palavra: ele não se encontra somente nas rotas tranqüilas e monótonas da longa duração [BRAUDEL, História e Ciências Sociais: a Longa Duração, 1958] (2011, p.113-114).
\end{abstract}

É assim que se oferece, com toda clareza, o modelo braudeliano da dialética das durações. A obra de Braudel, tomada isoladamente, apresenta-nos um "modelo teórico do tempo histórico" perfeitamente acabado. Em contrapartida, embora a criatividade aplicada aos modos de lidar com o tempo possa ser apontada como um dos mais fortes itens programáticos dos Annales, não se pode dizer que tal escola, como um todo, tenha produzido, efetivamente, uma maior unidade teórica que, das diversas experiências autorais desenvolvidas no movimento, tenha concretizado um sistema único. Dito de outra forma, não existe um modelo teórico do tempo histórico que unifique todos os annalistas paradigmaticamente. De todo modo, é importante ressaltar que o problema do tempo levou os historiadores dos Annales a oportunizar toda uma série de expressões e conceitos que podem ser evocados quando pensamos na questão das temporalidades. Entre esses, ocupam destaque as noções de evento, estrutura, duração, permanência e movimento.

Sobre o papel do "evento" no universo de modelos de compreensão do tempo que mais iremos encontrar nas realizações dos Annales - o traço comum a praticamente todos os historiadores do movimento quase se configurando em uma palavra de ordem é a já discutida crítica, em maior ou menor grau, à chamada História Eventual. Contudo, os annalistas se dividem com relação à possibilidade de interação entre Evento e Estrutura. Há, desde as propostas mais radicais que tentam levar a seus limites máximos a abordagem estrutural e praticamente excluir o evento, até as propostas que permitem 
um espaço de afirmação do acontecimento desde que dentro do quadro emoldurante da estrutura ou mesmo flutuando na polifonia de durações defasadas, até chegar a uma espécie de dialética da duração, à maneira de Braudel, ou seja, "dentro da qual o evento só existe porque estruturado" (REIS, 1994, p. 27).

Inserir o evento na estrutura corresponde pensar a mudança ou as diversas alterações no interior da grande permanência, sendo importante considerar que, dentro dessa concepção mais ampla, desdobram-se tendências e posicionamentos diversos com relação à possibilidade de trabalhar com a articulação entre Evento e Estrutura. Assim, uma primeira divisão de posicionamentos historiográficos poderia ser vislumbrada no próprio momento de fundação dos Annales, com as figuras-chave de Marc Bloch e Lucien Febvre. Este tendia a partir do evento e, então, estruturá-lo ou encontrar seu lugar na Estrutura. Bloch, de modo distinto, tendia a partir da Estrutura. Braudel, de certo modo, busca realizar uma síntese entre esses dois posicionamentos.

A função do evento estruturado ou do indivíduo notório que, em algumas obras de Febvre, podem insinuar questões sociais mais amplas - ou mesmo iluminar algo que não tardaria a ser chamado de "mentalidade coletiva"13 - faz desse historiador um caso singular, o que levou um de seus principais estudiosos, H. D. Mann, se referir a ele como um estruturalista "anti-estruturalista" (1971, p. 93-124). Suas obras sobre grandes personalidades como Rabelais (1942) ou Lutero (1953) confirmam essa leitura e correspondem ao modelo que elege o evento significativo para posterior estruturação ${ }^{14}$.

Alternativas igualmente inovadoras de relacionar evento e estrutura podem também ser encontradas nas contribuições de outros annalistas que lidaram com a "longa duração". Como já foi dito, o tempo estrutural permite conceber, no interior da estrutura, não apenas os acontecimentos, como também os processos que realizam reversibilidade, repetições e ciclos. Esse é o ponto de partida de uma tendência que se desdobra, posteriormente, ao modelo estrutural que parte de Marc Bloch. O historiador

\footnotetext{
${ }^{13}$ O conceito de "utensilhagem mental" aparece em alguns textos de Febvre, entre eles, Com reconstituir a vida afetiva de outras épocas (FEBVRE, 1941). A palavra "mentalidades" também aparece diversas vezes tanto em Febvre quanto em Bloch (ver, por exemplo, o artigo de Febvre intitulado História e Psicologia: uma visão de conjunto (1938), depois incorporado aos Combates pela História (FEBVRE, 1978 , p. 114). Também encontraremos nos dois fundadores dos Annales outras palavras com a mesma intenção, como "atmosfera mental" de uma época, tal como registra a Apologia da História, de Bloch (2001, p. 64).

${ }^{14}$ No artigo, cujo título é "Noção de Mentalidade em Bloch e Febvre", Burguière (1983) examina o contraste entre o modelo proposto por Febvre para a "análise da utensilhagem mental" que o aproxima de Henri Berr, e a abordagem que se desdobra de, pelo menos, uma das obras de Marc Bloch (Os Reis Taumaturgos), esta já se configurando como um prenúncio da História das Mentalidades que ainda estaria por vir dali a algumas décadas.
} 
da estrutura pode direcionar o seu olhar, precisamente, para os ciclos que se realizam no interior da estrutura, e esta busca esteve na origem de novas modalidades historiográficas como a História Serial e a História Quantitativa.

Posteriormente, as aberturas proporcionadas pela noção de "longa duração" chegarão, no limite, à possibilidade de propor uma "história imóvel", que será feita por Le Roy Ladurie em um artigo, de 1974, para a Revista dos Annales e em seu discurso de admissão para o Collège de France (1975). Devemos entender, todavia, que Ladurie não está de modo algum pretendendo chegar a uma ausência de movimento na História, em que esta perderia sua identidade mínima e terminaria por se converter em uma mera antropologia estrutural aplicada ao passado. Na verdade, Ladurie pretende é sustentar, com relação à história de alguns aspectos, que o historiador possa identificar "longas faixas de imobilidade", que parecem por um período considerável, suspender a história por alguns instantes, até que ela recomece com novos ritmos ${ }^{15}$.

Em Camponeses do Languedoc (1966), Ladurie procura examinar uma quase imobilidade de séculos no que concerne ao modelo de organização agrícola daquela região da França medieval. Para além disso, há, certamente, os casos de antigos microcosmos aldeães que, em função de um isolamento geográfico e de outras ausências de comunicação, parecem se situar à margem do tempo ou imobilizar-se em uma época passada. Em outra de suas obras, Ladurie dá-nos o exemplo de uma aldeia occitânica chamada Montaillou (1975), na qual o catarismo resistiu para muito além de seu desbaratamento na França do início do século XIII, chegando ao século XIV nessa pequena sociedade que também conservou outras estruturas arcaicas relacionadas ao modo de vida camponês e às antigas formas de parentesco. Com isto, essa aldeia tornouse uma espécie de ritardo de outro tempo, protegido pelas montanhas e pela inacessibilidade geográfica (LE ROY LADURIE, 1983) ${ }^{16}$.

Uma aldeia imóvel (1972) é precisamente o título de uma obra na qual Gérard Bouchard conseguiu encontrar, na Sologne do século XVIII, uma comunidade aldeã que parecia ter parado no tempo em pleno período iluminista. Para concluir, e isso já nos

\footnotetext{
${ }^{15}$ Para um comentário sobre o verdadeiro sentido da "história imóvel" de Le Roy Ladurie em sua conferência de admissão ao Collège de France (1975), ver VOVELLE, 2011, p. 394.

${ }^{16}$ Esse livro de Le Roy Ladurie, ao trabalhar com um microcosmo aldeão preservado para a historiografia por um detalhado processo inquisitorial, aproxima-se da perspectiva da micro-história. Com Montaillou uma aldeia occitânica entre 1294 e 1324 (1975), Le Roy Ladurie registra o seu deslocamento de uma historiografia que, na sua fase anterior, fora intimamente ligada ao modelo braudeliano, e que agora se configurava em uma nova Antropologia Histórica, conseguindo examinar, com maestria, uma pequena totalidade social - com inflexões sobre a cultura material, os modos de vida e os modos de pensar e de sentir - a partir da análise de um minucioso processo gerado pela Inquisição.
} 
leva ao próximo item a ser discutido, é importante lembrar que as possibilidades de perceber o tempo de novos modos também ajudaram os annalistas a repensarem de outra maneira a relação entre passado, presente e futuro.

\section{Presente e Passado: uma alteridade interativa}

A consciência da relação entre o Presente e o Passado é outro dos itens programáticos importantes para a Escola dos Annales. Marc Bloch lembrará que essa interação existe em duas vias, em uma passagem importante da Apologia da História (1943) - clássico livro para a compreensão do programa dos Annales. "Compreender o presente pelo passado", mas também "compreender o passado pelo presente", constituem as duas vias dessa complexa relação ${ }^{17}$. Marc Bloch também elabora, nesse mesmo livro, uma definição de História que se tornou clássica. Em oposição à antiga definição de que "a História é o estudo do passado humano", Bloch propunha a definição de que "a História é a Ciência dos homens no tempo". Dizer isso significa que não importa, rigorosamente, se o historiador estuda esta ou aquela época do passado, ou se pesquisa mesmo o presente, disputando território com os sociólogos e antropólogos. $\mathrm{O}$ que faria dele um historiador seria o fato de que pesquisa os homens imersos na temporalidade, vivendo, percebendo e produzindo o tempo. O mesmo historiador que estuda o passado, de acordo com essa perspectiva, poderia refletir acerca do tempo presente.

Por fim, uma última implicação do aforismo blochiano: nessa ciência dos homens no tempo, as temporalidades poderiam dialogar por meio da mediação do historiador. Fernand Braudel irá retomar essa ideia mais tarde, declarando ser ele mesmo "um historiador para quem a História é, ao mesmo tempo, conhecimento do passado e do presente, do 'tornado' e do 'tornar-se' (BRAUDEL, 1978, p. 235-236).

\footnotetext{
${ }^{17}$ Sobre o mesmo tema, Braudel escreveu dois artigos: "A História das Civilizações: o passado explica o presente" (1959) e "No Brasil Baiano: o presente explica o passado" (1959, p. 325-336), ambos depois incluídos em Escritos sobre a História (1969). Além disso, os historiadores da terceira geração dos Annales também pensaram a sua identidade reconhecendo como um item essencial essa nova forma de conceber a relação entre as duas temporalidades. No verbete sobre os "Annales" do Dicionário das Ciências Históricas (1986), Andrés Burguière chega a reconhecer esse aspecto como a principal contribuição dos Annales à historiografia: "Há[,] no entanto[,] alguma coisa de irreversível no modo pelo qual a prática dos historiadores se converteu ao 'espírito dos Annales', algo que merece o nome de revolução. Mais do que a renovação dos temas e objetos de pesquisa que propõe aos historiadores, é a mudança radical que preconiza em relação ao passado que define o paradigma dos Annales" (BURGUIËRE ,1993, p. 53).
} 
Um primeiro desdobramento a ser examinado no âmbito dessa nova "consciência historiográfica das temporalidades" é, de fato, a compreensão de que a História, mesmo se referindo ao passado, faz-se no presente. Não que tal ideia tenha surgido pela primeira vez com os Annales, mas não há como negar que, ainda no século XIX, o desdobramento mais renovador e relativista do paradigma historicista também apontou para esta consciência de que a História se produz a partir de um ponto de vista, inclusive, uma perspectiva pensada no tempo.

Além disso, o Presentismo de autores como Benedetto Croce (1866-1952) e outros já tinha produzido a célebre frase, ao chamar a atenção para o fato de que "toda história é contemporânea". Esta frase, pronunciada pela primeira vez por Croce, mas retomada mais tarde por Febvre em Combates pela História (1953), está prenhe de significados. A História - uma obra de História - seja ela ambientada na história antiga, na Iade Média, no início da Idade Moderna ou em qualquer outra época, é sempre uma "história contemporânea", porque é produzida na própria época do historiador, de acordo com as suas demandas e possibilidades.

No texto-manifesto no qual Febvre retoma o programa dos Annales (intitulado "Contra o Vento"), ele nos lembra, mais uma vez, o seu modelo de História por oposição a um outro, que considera o passado como algo dado. A sua História, a dos Annales, é "a que compreende e faz compreender; a que não é uma lição a ser aprendida a cada amanhã, com devoção - mas, sim, aquela que é de fato uma condição permanente da atmosfera" (FEBVRE, 2011, p. 83). Em seguida, no mesmo texto, Febvre reafirma a consciência de que a História é resposta às perguntas do Presente e delineia, com clareza, mais um dos desdobramentos da consciência da História como forma interativa entre Presente e Passado, duas instâncias que são diferentes uma da outra:

\begin{abstract}
A história, resposta às perguntas que o homem de hoje necessariamente se faz. Explicação de situações complicadas, em meio às quais ele debaterá menos cegamente caso conheça a origem. Lembrança de soluções que foram soluções no passado e que, portanto, não poderiam de modo algum ser as soluções do presente. Compreender bem em quê o passado difere do presente: que escola de flexibilidade para o homem alimentado de história [FEBVRE, Contra o Vento: Manifesto dos Novos Annales, 1946] (2011, p.83) ${ }^{18}$.
\end{abstract}

\footnotetext{
${ }^{18}$ Esse fecho parece nos remeter às Considerações Intempestivas (1876), de Friedrich Nietzsche, quando, no texto intitulado "Sobre a utilidade e os inconvenientes da história para a vida" (1873), o filósofo alemão insiste, mais do que tudo, em uma relação entre a História e a Vida.
} 
A História, que traz a consciência de que o passado é diferente do presente, conforme vemos, é bem distinta da História na qual o Presente pretende apreender do Passado uma velha lição. Febvre parece dar também o seu sutil recado a respeito da velha ideia da História como "mestra da vida". Ela tem algo a nos ensinar, mas não de maneira linear, como uma fórmula que pode ser sempre empregada, uma vez apreendida por meio de ciclos que sempre retornam. A História, parece frisar Febvre, não se repete. Uma lição que, pelo menos nesse aspecto, parece ter sido assimilada do paradigma historicista (os fatos não repetíveis), mas sem trazer, concomitantemente, a concepção de tempo na qual o Passado e o Presente estabelecem uma continuidade, isto é, um único fluxo no qual se esvanece o corte que poderia ser feito pela operação historiográfica.

No caso do modelo proposto pelos Annales, aprende-se com o Passado, precisamente, porque este é distinto do Presente. Sobretudo, é preciso que o historiador faça História mergulhado na vida - seja por estar emaranhado de sua própria época, seja por apreender do Passado o que há nele de vivo. Assim termina o Manifesto contra o Vento (1946):

\footnotetext{
Método histórico, método filológico, método crítico: belas ferramentas de precisão. Eles honram seus inventores e essas gerações de usuários que as receberam de seus antecessores e as aperfeiçoaram. Mas saber manejá-las, gostar de manejá-las - eis algo que não é suficiente para ser historiador. Apenas aquele que se lança na vida inteiramente - com o sentimento de que mergulhando nela, banhando-se nela, deixando-se impregnar, assim, pela humanidade presente - é digno deste belo nome; ele multiplica por dez suas forças de investigação, seus poderes de ressurreição do passado. De um passado que detém e que, em troca, lhe restitui o sentido secreto dos destinos humanos [FEBVRE, Contra o Vento: Manifesto dos Novos Annales, 1946] (2011, p.84).
}

Como estabelecer, entretanto, essa singularidade que é, ao mesmo tempo, um abismo e uma ponte entre duas temporalidades? A resposta está em pensarmos de maneira combinada e interativa dois dos itens programáticos dos Annales: a "consciência do tempo" e a "História-Problema". Presente e Passado são distintos, contudo, para além de estarem atravessados de vida e humanidade - o que já estabelece um certo território comum - ligam-se entre si por meio do Problema. Este, tal como deve ser ressaltado, é sempre formulado a partir do Presente e é por intermédio dele que se reconstrói, em um só movimento, o Passado examinado e o tempo histórico (uma periodização, um jogo de durações, uma estruturação específica). 
A ideia é que, com a operação historiográfica, se estabeleça uma comunicação mútua entre dois diferentes, na verdade entre dois mundos, de modo que, aqui, a perspectiva dos Annales opõe-se frontalmente ao padrão da História Positivista que tende a ver o Passado como um objeto analisado pelo historiador sem a ele retornar. Nos Annales, o Presente coloca as questões de sua época para o Passado, estruturando-o a partir de uma problematização e, reciprocamente, este Passado recoloca novas questões para o Presente, permitindo que, na operação historiográfica, não apenas o historiador compreenda o Passado, tal como ocorre na perspectiva historicista mais tradicional (neo-rankeana), mas também compreenda a si mesmo.

Essa consciência sobre a possibilidade de estabelecer uma reciprocidade entre as duas temporalidades, sem deixar de assumir a sua alteridade, foi posteriormente retrabalhada por autores diversos que não se identificam com os Annales, como Reinhart Koselleck (1979) e Paul Ricoeur (1983-1985). Além disso, como bem nos mostra André Burguière (1938), essa mesma consciência historiográfica acerca da alteridade interativa entre Presente e Passado prosseguiu como um item programático importante para a terceira geração dos Annales:

\begin{abstract}
Os Annales ajudaram o historiador a libertar-se da visão 'bela adormecida' de um passado condenado à sua própria reconstituição, com sua organização cronológica, à medida que o erudito exuma arquivos. $\mathrm{O}$ objeto da ciência histórica não é dado pelas fontes, mas construído pelo historiador a partir das solicitações do presente. Passado e presente se esclarecem reciprocamente a partir do momento em que a análise historiográfica estabelece uma relação 'generativa' (quando o historiador reconstitui a gênese de uma configuração presente) ou 'comparativa' (quando o efeito de distância entre uma forma de organização, um comportamento de uma outra época e seus equivalentes atuais permite comparar e conferir sentido à realidade social que nos cerca)" [BURGUIÈRE, verbete "Annales" do Dicionário de Ciências Histórica, 1986] (1993, p.53-54).
\end{abstract}

O problema da distinção entre as duas temporalidades também permite perceber uma diferença sutil entre a proposta de alguns dos historiadores dos Annales e o modelo de tratamento predominante no setor do Historicismo, que se inspira nas conquistas hermenêuticas de Wilhelm Dilthey (1833-1911) e, mais particularmente, de Hans-Georg Gadamer (1900-2002) por meio do viés heideggeriano. Recuperando toda uma contribuição histórica da hermenêutica até a sua época, Gadamer ultrapassa a perspectiva de Dilthey, a partir de Heidegger, e busca frisar que o historiador só pode "compreender", porque participa de uma tradição diante da qual deve se colocar, simultaneamente, como herdeiro e como intérprete. 
Dessa maneira, acompanhando a tendência geral do Historicismo, a hermenêutica gadameriana tende a incorporar Presente e Passado em uma contemporaneidade na qual se insere o historiador. Já os historiadores dos Annales, conforme já foi ressaltado, tendem a remarcar mais a distinção entre as duas temporalidades. Essas preocupações, nuançadas em unir ou separar os dois tempos, produzem uma distinção sutil, não avessa às porosidades e às possibilidades de acordo, mas que, de todo modo, acabam favorecendo, a cada lado, uma pauta de temas a serem tratados nas reflexões teóricas sobre as temporalidades.

Entre as discussões que mais preocupam os historiadores dos Annales está a ênfase na necessidade vital de evitar o anacronismo, o que é um sintoma significativo. Alguns dos integrantes da terceira geração do movimento que refletiram sobre o enigma das temporalidades tendem a ressaltar que o tempo histórico é percebido, como bem destaca Ariès em $O$ Tempo da História (1986), exatamente nessa surpreendente diferença entre o Presente e o Passado, ou, ainda, na distinção entre as várias estruturas entre si, consideradas sob a perspectiva de estruturas totais e fechadas que se sucedem. Desse modo, para retomar uma observação pertinente de José Carlos Reis, "o Passado e o Presente são diferentes que dialogam, e não a continuidade cumulativa do mesmo" (REIS, 1994, p. 26).

A noção muito forte de que o Passado é diferente em relação ao Presente - e de que cada época pode se diferenciar de uma outra como se fosse uma terra estrangeira pode ser ilustrada com os comentários de Lucien Febvre, em 1942, com sua obra intitulada O Problema da Descrença no século XVI: a religião de Rabelais (1968, p. 157). Ali, ele chama a atenção para o instrumental particular de cada civilização e ressalta que "nenhuma civilização está assegurada de poder transmitir essa outillage a épocas que vão lhe suceder". A França do século XVI, no que se refere a sua utensilhagem mental mais específica, pode ser tão diferente da França do século XX como, mal comparando, podem ser duas civilizações distintas ou duas nações estrangeiras. Por acreditar na importância de pensar a possibilidade desse abismo e de encontrar as pontes certas que permitiriam transpô-lo, Lucien Febvre dedicava especial cuidado em atentar para os riscos do anacronismo.

Em contrapartida, há outra questão fundamental da qual pode o historiador se beneficiar com relação à alteridade entre Presente e Passado. Se uma época passada pode ser considerada uma terra estrangeira para o historiador, haveria como tirar partido dessa situação (isto é, tratá-la como caminho e não como obstáculo)? Como fazer do 
"estranhamento" entre duas épocas um aliado da operação historiográfica? Fernando Braudel (1958), mas antes dele Philippe Ariès (1954), discutem essa questão a partir do conceito de "desenraizamento":

Philippe Ariès insistiu sobre a importância do sentimento de desenraizamento e de surpresa na explicação histórica: você imputa ao século XVI uma estranheza que é sua, homem do século XX. Porque essa diferença? O problema está colocado. Mas eu diria que a surpresa, o sentimento de desenraizamento, o distanciamento - esses grandes meios de conhecimento tampouco deixam de ser necessários para compreender aquilo que está ao nosso redor, e tão próximo que não chegamos mais a enxergá-lo com nitidez. Viva em Londres durante um ano, e você verá que mal conhece a Inglaterra. Mas, por comparação, à luz de uma certa capacidade de se espantar, será possível compreender bruscamente alguns dos traços mais profundos e originais da França, exatamente aqueles que não eram conhecidos por serem conhecidos demais. Diante do atual, o passado também é desenraizamento [BRAUDEL, História e Ciências Sociais: a Longa Duração, 1958] (2011, p.101-102).

É nessa equidistância em relação aos riscos do anacronismo e aos benefícios do desenraizamento que o historiador pode extrair a maior riqueza do seu ofício. $\mathrm{O}$ Tempo, como se vê, não é apenas matéria, forma ou instrumento para o trabalho historiográfico, mas também, em certa medida, um aliado para aquele que produz o conhecimento histórico. Com essa faceta, completam-se e complementam-se os sentidos da célebre frase de Marc Bloch: "a História é a ciência dos homens no tempo" - não apenas porque os seres humanos que se toma para análise estão mergulhados no tempo, como também em virtude de os próprios historiadores estarem sujeitados ao tempo, sendo precisamente isto o que torna possível a História. 


\section{REFERÊNCIAS}

ARIÈS, P. (1989). O Tempo da História. Rio de Janeiro: Francisco Alves [original: 1954].

ARIÈS, P. (1990). "História das Mentalidades" In: LE GOFF, J. (org.). A História Nova. São Paulo: Martins Fontes, p. 154-176. [original: 1978].

BAKHTIN, M. (1985). Cultura Popular na Idade Média e no Renascimento - o contexto de François Rabelais. São Paulo: Hucitec [original: 1941 / 1965].

BLOCH, M. (1993). Os Reis Taumaturgos - o caráter sobrenatural do Poder Régio. França e Inglaterra. São Paulo: Companhia das Letras [original: 1924].

BLOCH, M. (2001). Apologia da História. Rio de Janeiro: Zahar [original: 1941-42].

BOIS, P. (1970). Paysans de l'Ouest, des structures économiques et sociales aux options politiques depuis l'époque révolutionnaire. Paris / Haia: Mouton.

BRAUDEL, F. (1959-b). Dans les Brèsil Bahianais: le présent explique le passé. Annales ESC, ${ }^{\circ}$ 2. Paris: A. Colin, abr/jun, p. 325-336.

BRAUDEL, F. (2011). "História e Ciências Sociais: a Longa Duração". In: NOVAIS e SILVA (orgs.). Nova História em perspectiva. São Paulo: Cosac \& Naify, p. 87-127 [original: 1958].

BRAUDEL, F. (1984). O Mediterrâneo e o Mundo Mediterrânico. São Paulo: Martins Fontes [original: 1949, revisto em 1965].

BRAUDEL, F. (1978-b). "A História das Civilizações: o passado explica o presente". In: Escritos Sobre a História. São Paulo: Perspectiva, p. 235-288 [original: 1959].

BURGUIÈRE, A. (1993) «Annales » In: Dicionário das Ciências Históricas. Rio de Janeiro: Imago [original: 1986].

BURGUIÈRE, A. (1983). La notion de 'mentalités' chez M. Bloch et L. Febvre: deux conceptions, deux filiations. Revue de Synthèse, $n^{\circ}$ 111/112. Paris: CIS/CNRS, jul/dec.

FEBVRE, L. (1928). Martin Luther: un destin. Paris: PUF.

FEBVRE, L. (1941). Comment reconstituer la vie affective d'outre fois. Annales d'Histoire Sociale, III. Paris.

FEBVRE, L. (1968). Le problème de l'incroyance au XVI siècle - La Religion de Rabelais. Paris: A. Michel [original: 1942].

FEBVRE, L. (1978-a). História e Psicologia. In; MOTA, C. G. e FERNANDES, F. Febvre. São Paulo: Ática, p. 68-83 [original: 1938]. 
FEBVRE, L. (2011). "Face ao Vento: manifesto dos novos Annales" In: NOVAIS, F. e SILVA, R. Nova História em perspectiva. S. Paulo: Cosac \& Naify, p. 75-85 [orig: 1946].

FOUCAULT, M. Arqueologia do Saber. Rio de Janeiro: Forense Universitária, 1995 [original: 1969].

FRANCASTEL, P. (1990). Pintura e Sociedade - nascimento e destruição de um espaço plástico. São Paulo: Martins Fontes [original: 1951].

GINZBURG Carlo. (1989-a). O Queijo e os Vermes. São Paulo: CIA das Letras [original: 1976].

HOBSBAWM, E. e RANGER, T. (1997). A invenção das tradições. São Paulo: Paz e Terra [original: 1983].

KOSELlECK, R. (2006). Futuro Passado - contribuição à semântica dos tempos históricos. Rio de Janeiro: Contraponto [original: 1979].

LE ROY LADURIE, E. (1966). Les paysans de Languedoc. Paris: S.E.V.P.E.N.

LE ROY LADURIE, E. (1974). L’Histoire Immobile. Annales ESC n³. Paris: A. Colin, mai/jun.

LE ROY LADURIE, E. (1978-b). L'Histoire Immobile [aula inaugural para o Collège de France]. In: Le Territoire de l'historien. Paris: Gallimard.

LE ROY LADURIE, E. (2011). "Acontecimento e Longa Duração na História Social: o exemplo dos chouans" In: NOVAIS, F. e SILVA, R. (orgs.). Nova História em perspectiva. S. Paulo: Cosac \& Naify, p.248-267 [orig: 1972].

LE ROY LADURIE, E. (1973). Un concept: L'Unification microbienne du monde. Revue d'histoire suisse, $23, n^{\circ} 4$.

LE ROY LADURIE, E. (1983). Montaillou: cátaros e católicos em uma aldeia francesa. Lisboa: Edições 70 [original: 1975].

MANDROU, R. (1979). Magistrados e feiticeiros na França do século XVII, São Paulo: Perspectiva [original: 1968].

MANDROU, Robert. De la culture populaire aux XVIIe et XVIIIe siècles. Paris : Stock, 1975.

MANN, H-D. (1971). Febvre, la pensée vivante d'une historien. Paris: A. Colin.

NIETZSCHE Friedrich. (2005). "Da Utilidade e Desvantagem da História para a Vida". In: Escritos sobre a História. Rio de Janeiro: Loyola [original: 1874].

POMIAN, K. (1990). A História das Estruturas. In: LE GOFF, Jacques (org.). A Nova História. São Paulo: Martins Fontes [original: 1978]. 
REIS, J. C. (1994-a). Nouvelle Histoire e Tempo Histórico. São Paulo: Ática.

RICOEUR, Paul (2011). Tempo e Narrativa. São Paulo: Martins Fontes [original: 1983-1985].

VOVELlE, M. (2011). "História e Longa Duração". In: NOVAIS e SILVA (orgs.). Nova História em perspectiva. São Paulo: Cosac \& Naify, p.371-407 [original: 1979].

WALLERSTEIN, I. (1991). "The invention of time-space realities: Towards an understanding of our Historical Systems”. In: Unthinking Social Science. Cambridge: Polity Press. 